\section{Rheumatoid Cachexia: What Is It and Why Is It Important?}

\section{To the Editor:}

We were delighted that rheumatoid cachexia (RC), the condition of reduced muscle mass and increased fat mass associated with rheumatoid arthritis (RA), received editorial attention in the March issue of The Journal $^{1}$. As pointed out by Rajbhandary, et al, while RC is evident in the majority of patients with RA, and is a key contributor to the patient's disability, increased morbidity, and premature mortality, this important feature of RA receives disproportionately little clinical consideration. Thus, all efforts to highlight the clinical significance of RC are to be applauded. However, we consider it necessary to comment on several conclusions in this editorial, which, left unchallenged, will mislead readers unfamiliar with the subject.

Rajbhandary, et al state that "anti-TNF- $\alpha$ [tumor necrosis factor- $\alpha$ ] therapy is an intervention that seems to improve RC," and substantiate this claim by reference to results from one of our studies ${ }^{2}$. However, this conclusion is not supported by either our findings or those of subsequent investigations $\mathrm{s}^{3,4}$, as none of these studies observed improvements in lean body mass in patients with RA following anti-TNF therapy. Further, the investigations of Metsios, $e t a l^{3}$ and Engvall, et $a l^{4}$, disturbingly, noted significant increases in trunk fat mass and total fat mass in patients treated with anti-TNF agents. Thus, current findings do not support the use of antiTNF therapy specifically to counter RC.

The editorial also claims that "studies have shown that increased protein intake would be helpful for overcoming the catabolic process in RA, particularly when combined with an exercise intervention," and refers to another of our studies ${ }^{5}$ as the supporting reference. While we agree that the combination of protein supplementation and exercise is likely to be successful in reversing the adverse body composition changes of $\mathrm{RC}$, this effect has not been shown, as our intervention did not include exercise, and to our knowledge this combined intervention has yet to be trialled in patients with RA. The authors and title of our report were also incorrectly transcribed in the editorial - readers are directed to the reference list below to find the correct biographical details.

Additionally, although correctly stating that high-intensity progressive resistance training (HI PRT; i.e., weight training) is efficacious in reversing the adverse effects of RC on body composition, Rajbhandary, et al fail to reference any of the studies (e.g., Marcora, et $a l^{6}$, Hakkinen, et $a l^{7}$, Lemmey, $e t a l^{8}$ ), including a randomized controlled trial performed by our group $^{8}$, that have shown this to be the case. [Each of the studies referenced $^{6,7,8}$, among others, has shown substantial increases in lean body mass and reductions in fat mass following HI PRT.] Instead, the study they do refer to is that of Rall, et $a l^{9}$, which, alone among studies investigating the effects of HI PRT on RC, reports no changes in body composition following training. We do, however, agree with their conclusion that HI PRT "is the best way to improve muscle strength and physical functioning in patients with RA" and "should be routinely prescribed and maintained."

Speculating on the etiology of $\mathrm{RC}$, the editorial refers to one of our reports ${ }^{10}$ that described reduced serum insulin-like growth factor-I (sIGF-I) levels, and echoes our conclusion at the time that these diminished levels may contribute to RC. However, these earlier postulations have been superseded by our finding that attenuated muscle levels of IGF (mIGF-I, mIGF binding protein-3) are much more likely to be involved in the mechanism underlying $\mathrm{RC}^{8}$.
Finally, we were surprised and disappointed that, in an area of research where there has been a recent upsurge in interest, the editorial relied almost exclusively on old references (i.e., 18 out of 19 references were from 2006 or before; 13 of 19 were from 2002 or before), and thus overlooked important recent developments in the field.

ANDREW B. LEMMEY, PhD; JEREMY JONES, MD; PETER J. MADDISON, MD, School of Sport, Health and Exercise Sciences, Bangor University, Bangor, Gwynedd UK, LL57 2PZ. Address correspondence to Dr. Lemmey: E-mail: a.b.lemmey@bangor.ac.uk

\section{REFERENCES}

1. Rajbhandary R, Khezri A, Panush RS. Rheumatoid cachexia: What is it and why is it important? [editorial]. J Rheumatol 2011; 38:406-8.

2. Marcora SM, Chester KR, Mittal G, Lemmey AB, Maddison PJ. Randomised phase 2 trial of anti-tumor necrosis factor therapy for cachexia in patients with early rheumatoid arthritis. Am J Clin Nutr 2006;84:1463-72.

3. Metsios GS, Stavropoulos-Kalinoglou A, Douglas KM, Koutedakis Y, Nevill AM, Panoulas VF, et al. Blockade of tumor necrosis factor alpha in rheumatoid arthritis: effects on components of rheumatoid cachexia. Rheumatology 2007;46:1824-7.

4. Engvall I-L, Trengstrand B, Brismar K, Hafstrom I. Infliximab therapy increases body fat mass in early rheumatoid arthritis independently of changes in disease activity and levels of leptin and adiponectin: a randomised study over 21 months. Arthritis Res Ther 2010;12:R197.

5. Marcora SM, Lemmey AB, Maddison PJ. Dietary treatment of rheumatoid cachexia with $\beta$-hydroxy-ß-methylbutyrate, glutamine and arginine: a randomised controlled trial. Clin Nutr 2005; 24:442-54.

6. Marcora SM, Lemmey AB, Maddison PJ. Can progressive resistance training reverse cachexia in patients with rheumatoid arthritis? Results of a pilot study. J Rheumatol 2005;32:1031-9.

7. Hakkinen A, Pakarinen A, Hannonen P, Kautiainen H, Nyman K, Kraemer WJ, et al. Effects of prolonged combined strength and endurance training on physical fitness, body composition and serum hormones in women with rheumatoid arthritis and in healthy controls. Clin Exp Rheumatol 2005;23:505-12.

8. Lemmey AB, Marcora SM, Chester K, Wilson S, Casanova F, Maddison PJ. Effects of high-intensity resistance training in patients with rheumatoid arthritis: A randomised controlled trial. Arthritis Rheum 2009;61:1726-34.

9. Rall LC, Meydani SN, Kehayias JJ, Dawson-Hughes B, Roubenoff $\mathrm{R}$. The effect of progressive resistance training in rheumatoid arthritis. Increased strength without changes in energy balance or body composition. Arthritis Rheum 1996;39:415-26.

10. Lemmey AB, Maddison PJ, Breslin A, Cassar P, Hasso N, McCann $\mathrm{R}$, et al. Association between insulin-like growth factor status and physical activity levels in rheumatoid arthritis. J Rheumatol 2001;28:29-34.

J Rheumatol 2011;38:9; doi:10.3899/jrheum.110308 